\title{
EXACCION DE LA CUOTA EMPRESARIAL DEL REGIMEN ESPECIAL AGRARIO DE LA SEGURIDAD SOCIAL POR BIENES MUNICIPALES
}

$368.4: 631(46)$

por

\section{Leocadio-Manuel Moreno Páez}

Colaborador del Instituto de Estudios de Administración Local

SUMARIO: I. ANTECEDENTES.-II. ACTUACIONES.-III. CONCLUSIONES.

\section{ANTECEDENTES}

Con anterioridad a la promulgación de la Ley de 31 de mayo de 1966 y Reglamento de 23 de febrero de 1967, reguladores ambos del Régimen Especial Agrario de la Seguridad Social, ya existía planteado el problema que más tarde ha adquirido singular relevancia, tanto por su extensión como por su alcance.

En el régimen anterior, al ser las cuotas de una cuantía notablemente inferior, una gama extensa de Ayuntamientos no las reclamaron, pero otro número muy importante de ellos, especialmente aquellos cuyos aprovechamientos forestales eran de carácter resinero, solicitaron y obtuvieron la declaración de exención, a tenor del artículo 15 de la Orden de 3 de febrero de 1949, dictada para la regulación de las cotizaciones a este sistema de Seguridad Social.

$\mathrm{Al}$ regularse este régimen especial por Ley de 31 de mayo de 1966 (Ley de la Seguridad Social Agraria) y Reglamento de 23 de febrero de 1967 (Reglamento de la Seguridad Social Agraria), se señaló una cotización consistente en un 15,9 por 100 sobre la base imponible aplicable a la Contribución Territorial Riqueza Rústica, tanto por ciento que quizá no fue meditado, y que si lo fue, dio lugar a un oneroso gravamen, al ser uniforme en todos los sujetos pasivos sometidos al pago de la Contribución Territorial Riqueza Rústica. 
Hay que resaltar un hecho que puede centrar la cuestión que más adelante se ha convertido en un señalado y controvertido problema. Habiendo alcanzado por razones ocasionales un alto valor los productos forestales, como consecuencia del aislamiento económico de nuestra nación, del incremento de la construcción y de la no importación de diferentes materias, y coincidir en la mayoría de los casos la totalidad de las más amplias explotaciones forestales madereras y resineras en manos de Municipios, Entidades locales menores, Mancomunidades intermunicipales, Juntas administrativas y propietarios de montes de los denominados «en mano común», y existir en muchas de estas Entidades públicas un régimen de aprovechamientos comunales en favor de los vecinos, las Entidades jurídicas tutelares de los montes se encontraron con la doble premisa de ser propietarios teóricos de unos bienes cuyo rendimiento había sido altamente valorado en un momento de emergencia por razones de política económica nacional, y por otra parte, y en sentido absolutamente contrario, ir a parar el rendimiento de estos bienes no a sus cajas, sino al bolsillo de los vecinos con derecho a los aprovechamientos, y las Corporaciones cargar con las cuotas empresariales.

La cuota empresarial supuso para las Corporaciones propietarias de montes públicos una incidencia económica de extrema gravedad, que más que el pago de una cuota de Seguridad Social que se hubiese satisfecho en función de relaciones laborales y para los trabajadores que lo hiciesen en favor de las mismas, se transformaba en una cuota de carácter fiscal, fija por la cuantía y periódica por el vencimiento, y, como hemos afirmado, extremadamente onerosa.

Tardó en producirse una reacción generalizada, aunque ya en 1968 y en los meses de mayo y julio se produjeron reuniones de Alcaldes, Procuradores en Cortes representativos de los Municipios de varias Provincias y otros representantes funcionarios, que, aunque no preocupados concretamente en aquel entonces exclusivamente por el tema de la Seguridad Social Agraria, abordaron el mismo, y aunque es cierto que por razones coyunturales aquellas reuniones no se continuaron, sí lo es que fue entre los representantes en Cortes de las Provincias asistentes, entre los que se produjo un movimiento que cristalizó en reclamaciones cuyo detalle vamos a procurar analizar a lo largo de este estudio.

Debemos añadir, como luego definió con un magnífico contenido doctrinal la sentencia de la Sala Tercera del Tribunal Supremo de 16 de diciembre de 1972 (Aranzadi 5136), que tanto en el texto de la 
Ley de la Seguridad Social Agraria como en el del Reglamento de la Seguridad Social Agraria existian razones igualmente en pro y en contra para, cuando menos aparentemente, considerar y defender la inclusión o exclusión de las Corporaciones locales poseedoras de montes públicos catalogados, o bienes forestales de distinto aprovechamiento, del pago de la cuota empresarial del Régimen Especial Agrario de la Seguridad Social.

Esto va centrando el problema, que no es otro que el de la aparición de dos posturas contrapuestas:

A) La de los órganos gestores de la Seguridad Social Agraria, que, amparados en concretos y determinados preceptos, tanto de la Ley de la Seguridad Social Agraria como del Reglamento de la Seguridad Social Agraria, entendían, y siguen porfiadamente defendiendo, que el hecho de figurar como contribuyentes por rústica obligaba al pago de la cuota empresarial, e igualmente que por el simple hecho de la tenencia material de la tierra, y, en todo caso, por tener trabajadores o asalariados dedicados a labores agrícolas, se era "empresa agraria».

B) La de las Corporaciones que mantienen que, estableciéndose tanto en la Ley de la Seguridad Social Agraria como en el Reglamento de la Seguridad Social Agraria, las obligadas al pago eran las «empresas agrarias», al no aparecer constituidas empresas de esta índole, y al no tener los poseedores de la tierra, en este caso montes públicos catalogados, empresa, ni emplear trabajadores, ni obreros fijos, ni asalariados de clase alguna, al servicio de aquéllas, no estaban obligados o, lo que es lo mismo, no sujetos al pago de la referida cuota empresarial.

Debemos matizar dos contornos que pueden ser la clave de la solución dada por la doctrina jurisprudencial a los casos debatidos. Mientras que en la Orden de 3 de febrero de 1949 se estableció una «exención» en favor de determinadas categorías y explotaciones de bienes forestales, caso concreto el de los aprovechamientos resineros, en la Ley de la Seguridad Social Agraria y en el Reglamento de la Seguridad Social Agraria se hacía referencia a la sujeción al pago de la cuota empresarial, de las «empresas agrarias», sin un concepto absolutamente claro.

Decimos esto porque al plantearse por primera vez el problema, y seguramente por un defecto de expresión, sin duda alentadas por la supuesta vigencia del artículo 15 de la Orden de 3 de febrero 
de 1949, hubo Corporaciones que solicitaron la exención, cuando en realidad lo que debieron solicitar, y lo que querían obtener, era la exclusión, es decir, la no sujeción al pago de la cuota empresarial, en atención a no ser la Corporación solicitante ni estar constituida en «empresa agraria».

Por conocimiento a través de los asistentes a cursos de habilitación y perfeccionamiento, el Instituto de Estudios de Administración Local ha tenido noticia de esta cuestión, y por sus órganos directivos se ha creído conveniente estudiar el tema. Ello es lo que se ha querido.

\section{ACTUACIONES}

Partiendo del anterior planteamiento, las Corporaciones hicieron uso de dos procedimientos:

1. Muchas de ellas, y puesto que las cuotas les eran exigidas a través de los servicios recaudatorios de la Delegación de Hacienda, interpusieron reclamaciones económico-administrativas ante los Tribunales provinciales de esta jurisdicción, y contra las resoluciones de las mismas el recurso contencioso-administrativo ante las Salas de lo Contencioso de las Audiencias Territoriales o ante la Sala Tercera del Tribunal Supremo, cuando las resoluciones económico-administrativas fueron dictadas por el Tribunal Central de esta especialidad.

2. Otras Corporaciones acudieron directamente a solicitar de la Dirección General de la Seguridad Social del Ministerio de Trabajo la exención, y ahí está el error que anteriormente hemos apuntado, y otras, solicitando la no inclusión. Las resoluciones dictadas por la Dirección General de la Seguridad Social fueron denegatorias, recurridas en alzada ante el Ministerio de Trabajo, que resolvió confirmando las apeladas, y agotada la vía administrativa, recurridas ante la jurisdicción revisora, Sala Cuarta del Tribunal Supremo.

Las resoluciones dictadas dieron lugar a pronunciamientos muy variados, que vamos a procurar concretar.

Primero. Las reclamaciones formuladas ante el Tribunal Provincial Económico-administrativo de Segovia fueron resueltas en favor de las Corporaciones reclamantes, que alcanzó a la inmensa mayoría de las afectadas en aquella Provincia y en las declaraciones 
de las resoluciones se concretó, en primer lugar, que dicho Tribunal provincial era competente para conocer de las mismas, y una vez centrada la cuestión de fondo, que por no ser ni estar constituidas las Corporaciones reclamantes en «empresa agraria», no estaban obligadas al pago de la cuota empresarial del Régimen Especial Agrario de la Seguridad Social en razón de no reunir las características exigidas en la Ley de la Seguridad Social Agraria y Reglamento de la Seguridad Social Agraria, a que tan insistentemente nos venimos refiriendo.

Segundo. Otros Tribunales provinciales se declararon incompetentes para conocer por razón de la materia, al entender que no teniendo otra vinculación la cuota empresarial con la contribución territorial que la de ser cobradas en un mismo recibo, aunque por los mismos procedimientos coactivos que las exacciones estatales, no gozabán los obligados al pago de los mismos derechos que los concedidos a los contribuyentes. Al declararse no competente no entraba a conocer en el fondo del asunto, y las resoluciones concedían a los reclamantes la posibilidad de revisar los pronunciamientos de aquéllos ante la jurisdicción contencioso-administrativa.

Tercero. A la hora de la revisión de estas resoluciones hubo sentencias contradictorias. Mientras que la Sala de lo Contenciosoadministrativo de la Audiencia Territorial de Burgos se pronunció revisando los acuerdos del Tribunal Provincial Económico-administrativo de Soria, en el sentido de declarar la competencia del Tribunal y entrar a conocer del fondo del asunto, declarando que, por no darse el supuesto de existencia de "empresa agraria», las Corporaciones reclamantes no estaban obligadas al pago de la cuota empresarial, y su baja de los padrones de la misma correspondientes a 1967, período al que se referían las reclamaciones, otras Salas de diferentes Audiencias Territoriales, para dar una nueva oportunidad a la Administración de pronunciarse, declararon la competencia de los Tribunales provinciales, la nulidad de lo actuado y que volviesen los expedientes para nueva reconsideración, partiendo ya del principio de que eran competentes para conocer de la cuestión planteada, a conocimiento de los mismos.

Esta postura de las Salas de lo Contencioso fue, en el caso de Burgos, complementada al tratarse de reclamaciones de menor cuantía y no haberse interpuesto recurso en interés de doctrina, pero en aquellas sentencias de las Audiencias en que se dio opor- 
tunidad a los Tribunales de nuevo pronunciamiento, y aun declarándose competentes, no dieron lugar al recurso en cuanto al tondo, con lo que las Corporaciones recurrentes hubieron de volver a seguir la vía contencioso-administrativa, y obtener, como obtuvieron, sentencias favorables, dictadas por las Audiencias Territoriales de Burgos, Valladolid, Albacete, Valencia, Sevilla y Madrid, entre otras.

Hay que consignar un hecho curioso. Como en el período de trámite que media entre la reclamación económico-administrativa, su resolución y la tramitación del recurso contencioso-administrativo, transcurre un espacio de tiempo que en la mayoría de los casos ha sido superior a un año, y en muchos casos a dos y tres ejercicios, tanto la Delegación de Hacienda como los órganos rectores de la Seguridad Social, a pesar de haber obtenido las Corporaciones sentencias favorables respecto a un ejercicio, les han seguido girando las cuotas con referencia a los posteriores, y así, quien obtuvo una sentencia favorable para 1967, ha tenido que interponer otros recursos para los años 1968, 1969, 1970, 1971 y 1972; extraña, enorme y antijurídica situación que reiteradamente se ha señalado y que, por el juego de la institución revisora que la jurisdicción contencioso-administrativa entraña, parecía no tener solución.

Cuarto. No obstante, algunos reclamantes, esgrimiendo una tesis basada en principios de Derecho fiscal, entendieron que si bien en las pretensiones procesales ante las Salas de lo Contencioso no podian solicitarse declaraciones de futuro, lo cierto es que tanto en la Ley General Tributaria, como en las leyes y procedimientos económico-administrativos en general, cuando se causa baja en un padrón de un impuesto o tasa no puede producirse nueva alta a menos que no se realice una declaración del contribuyente, considerándose sujeto y obligado a ser incluido en el padrón en que se le concedió la baja, o que la Administración, haciendo uso de sus mecanismos inspectores, proceda mediante actuación en este sentido a dar de alta a aquel cuya situación haya cambiado en relación con la existente en el momento de la baja.

Prosperó esta tesis, y varias sentencias de la Audiencia Territorial de Valladolid, entre ellas las de 27 de febrero de 1971 y 7 de octubre del mismo año, declararon que las Corporaciones recurrentes fuesen dadas de baja en los padrones de la cuota empresarial, hasta tanto que no se constituyesen en «empresas agrarias», sin 
perjuicio del derecho de la Administración a investigar por medio de sus servicios de inspección si la situación existente al dictarse la sentencia se había modificado. No es una declaración de futuro, pero sí es un útil remedio para evitar una flagrante injusticia.

Quinto. En el intervalo de las dos sentencias dictadas en las fechas indicadas, la última de las cuales, la de 7 de octubre de 1971, fue confirmada en todas sus partes por la de la Sala Tercera del Tribunal Supremo de 16 de diciembre de 1972 (Aranzadi 5136), se produjo la sentencia de 23 de marzo de 1971 (Aranzadi 1723), en la que se estableció la doctrina de que para ser incluidas las Corporaciones locales como sujetos pasivos de la cuota empresarial de la Seguridad Social Agraria, era preciso que ocurriesen hechos de varia índole, y aunque en principio cabe la posibilidad de que las Corporaciones locales fuesen «empresas agrarias», podían serlo de dos formas, «empresa agraria expresa» y «empresa agraria tácita», siendo las primeras las que de una manera perfectamente definida figurasen en los censos laborales y sindicales como tales, y tácitas aquellas que sin figurar en los padrones, ocupasen trabajadores por cuenta ajena en labores agrarias.

Tras la sentencia de 23 de marzo de 1971 (Aranzadi 1723), el concepto de «empresa agraria» se configuraba relacionando el artículo 39 de la Ley de la Seguridad Social Agraria con el párrafo primero del artículo 46 de la misma, y dentro del ámbito personal del artículo 4, y en todo caso se precisaba:

- Ocupar trabajadores por cuenta ajena en labores agrícolas.

- Existencia del binomio "empresario-trabajador».

- Existencia de empresa o "explotación agraria» para llevar a cabo negocios o proyectos, según las cristalinas definiciones del diccionario de la Real Academia.

Por otra parte, una copiosa y abundante jurisprudencia de las Salas de lo Contencioso-administrativo lo ha entendido así con anterioridad y posterioridad al pronunciamiento de la Sala Cuarta. Así las sentencias de 22 de enero de 1969, doce en total, de la Sala de la Territorial de Burgos; más de diez de la Sala de Madrid, entre otras, la de 5 de noviembre de 1971, y una serie de más de veinte pueblos de la Provincia de Valladolid, en recursos vistos por aquella Territorial y Sala, debiendo citar las sentencias de 27 de febrero de 1971, cuatro en total; 4 de julio de 1970, 7 del mismo mes y año, 29 de septiembre, 2 de octubre y 22 de noviembre del mismo año. 
Sexto. De acuerdo con la doctrina de la Sala Cuarta del Tribunal Supremo en sentencia ya citada de 23 de marzo de 1971 (Aranzadi 1723), las Salas de lo Contencioso-administrativo dictaron nuevas sentencias, ratificándose unas y pronunciándose de nuevo otras, recogiendo los postulados que en el apartado precedente acabamos de indicar, y una larga serie de ellas dio lugar a una variada gama de recursos que en algunas Provincias, concretamente en la de Guadalajara, afectó a más de 70 Municipios, que obtuvieron sentencias favorables a su postura, si bien referidas a períodos anuales determinados.

Séptimo. El Consejo de Ministros, a propuesta de los órganos gestores de la Seguridad Social Agraria, declaró la lesividad de los acuerdos del Tribunal Provincial Económico-administrativo de Segovia a que antes nos hemos referido, y en virtud de la misma se interpuso recurso contencioso-administrativo ante la Audiencia Territorial de Madrid, que fue desestimado.

No conforme con esta resolución, tanto el abogado del Estado como la representación del Instituto Nacional de Previsión, órgano gestor de la Seguridad Social Agraria, recurrieron ante el Tribunal Supremo, quien en sentencia de 15 de diciembre de 1972, Sala Tercera (Aranzadi 5121), declaró:

a) Que los Tribunales Económico-administrativos son competentes para conocer de los actos de gestión y cobro de las cuotas individualizadas atribuidas a las empresas en el Régimen Especial Agrario de la Seguridad Social.

b) Se reitera que para ser sujeto pasivo de la cuota es preciso ser o estar constituido en "empresa agraria» o ser titular el obligado de una explotación agraria, reputándose empresario, en cualquier caso, a quien ocupe trabajadores por cuenta ajena en labores agrarias.

c) Que se reitera totalmente que la fórmula de la Seguridad Social no es otra cosa que «un contrato de seguro obligatorio por razones y finalidades de orden social».

d) Que a esto debe añadirse que, por razones procedimentales, el camino de las Corporaciones al acudir a los Tribunales Provinciales Económico-administrativos era absolutamente adecuado.

Octavo. Hemos hecho anteriormente referencia a una modalidad de sentencia dictada por la Sala de lo Contencioso de la Audiencia Territorial de Valladolid que dio lugar a la sentencia de la Sala 
Tercera del Tribunal Supremo de 16 de diciembre de 1972 (Aranzadi 5136), que más claramente define y resuelve todos los problemas planteados. El ponente de la misma fue el Excmo. Sr. D. Angel Martín del Burgo Marchán, quien en la misma, y a lo largo de unos fundamentados considerandos, resolvió las siguientes cuestiones:

1. Que no era preciso a las Corporaciones locales verificar el previo pago para reclamar contra la inclusión de las mismas en los padrones de la cuota empresarial del Régimen Especial Agrario de la Seguridad Social, en razón a varios presupuestos en los que priman, de un lado el imponerse no una cuota definitivamente liquidada, sino referirse el litigio al hecho de la inclusión o no de las Corporaciones reclamantes en los padrones de la cuota referida.

2. Que superados los artículos propuestos como causa de inadmisibilidad, debió de entrarse a conocer sobre el fondo del asunto que presentaba diversos supuestos entre los que cabía señalar:

a) Si los actos relacionados con esta materia y susceptibles de impugnación podrían o no ser residenciados ante los Tribunales Económico-administrativos.

b) Como problema ya más concreto, si en el caso suscitado en el recurso a que se refería la sentencia, el Ayuntamiento indicado debía quedar sujeto al devengo de esta cuota de la Seguridad Social Agraria.

3. Que prescindiendo de un positivismo ya superado que impide olvidar que lo jurídico no se encierra y circunscribe a las disposiciones escritas, sino que se extiende a los principios y a la normatividad inmanente en la naturaleza de las instituciones, se trae esta cita a colación en razón a que a pesar de ser muy conocida, adquiere especial relevancia en este caso, en que las dos tesis en debate cuentan con apoyaturas de cierta solidez, si es que nos limitamos sólo a ver el conjunto de disposiciones legales en favor de una y otra posición.

4. Que ante este antagonismo de posturas dialectivas y de normaciones, un tanto neutralizantes en sus efectos, se impone, como se ha apuntado, elevarse del plano normativo al superior de los principios y de las ideas cardinales de las instituciones en debate; ello nos permite situar por delante y poner en juego el principio integrador del binomio prerrogativa-garantía, para hacer viable en términos de derecho el funcionamiento de la primera, sin menoscabo o destrucción de la segunda; y nos sirve, en el caso concreto de autos, para comprender que si al instaurar el nuevo sistema de la 
Seguridad Social Agraria se ha preferido servirse para su efectividad del mecanismo existente para la gestión de un determinado impuesto -la Contribución Territorial Rústica- es no sólo porque dichas cuotas permiten actuarse en esas vías como si fueran «recargos», sino porque el sistema permite disponer del procedimiento más adecuado y eficaz en la defensa de los contribuyentes: vía económicoadministrativa y jurisdiccional después.

5. Que en cuanto a lo primero, la técnica empleada ha consistido en "asimilar» las cuotas de la cotización empresarial de la Seguridad Social Agraria a las de la citada contribución -artículo 46, $4 .^{\circ}$ de la Ley de 31 de mayo de 1966-; ahora bien, como no es imaginable que el legislador opere con las instituciones jurídicas sin un respeto, mínimo al menos, a las exigencias de la naturaleza de éstas, no es concebible que tal asimilación se haya hecho sin un previo conocimiento de la compatibilidad existente entre tales "cuotas", lo cual exige a su vez que éstas no sean del todo heterogéneas; y no lo son, en el presente caso, porque si las cuotas de la Contribución Territorial son inequívocamente cuotas tributarias, por tratarse de uno de los impuestos más definidos y de más solera en nuestro sistema tributario, las otras cuotas, la de los autos, de la Seguridad Social Agraria, si no reunen tales requisitos, sí, al menos, presentan la nota mínima de su carácter parafiscal, y por ello, al ser exacciones parafiscales, que es lo que les permite presentar un material nuclear con afinidades suficientes para poder construir la «asimilación» decretada por el legislador.

6. Que no se opone al carácter que acabamos de atribuir a la cuota en litigio, el hecho de que en el apartado $4 .^{\circ}$ del artículo 2 de la Ley de Tasas y Exacciones parafiscales, de 26 de diciembre de 1958, se excluya de la aplicación de esta Ley, entre otras exacciones, a «las cuotas y percepciones de la Previsión Social, seguros sociales obligatorios, Montepíos laborales y Mutualidades de toda clase», puesto que, como ha interpretado la doctrina, esta exclusión no implica un rechazo del carácter de exacción parafiscal de estas percepciones, sino la distinción entre las tasas y exacciones sometidas al régimen general o común de dicha Ley, y las sujetas a regímenes especiales, como ocurre con la debatida en este proceso.

7. Que no es correcto tratar de invalidar la anterior argumentación con el razonamiento de que dicha "asimilación" se produce por la Ley en forma muy limitada y restringida, sólo a efectos recaudatorios, pues aunque esto sea cierto, si la norma se contempla 
muy a ras de tierra («a efectos de que le sean de plena aplicación las normas y procedimientos recaudatorios de aquellas», refiriéndose a la tan citada Contribución Territorial, según reza la mencionada Ley de 31 de mayo de 1966, en el apartado $4 .^{\circ}$ de su artículo 46), no debe olvidarse que el entronque de una cuota con otra es más íntimo que todo eso, por no corresponder sólo a una fase o a una incidencia del procedimiento general de gestión de la mencionada Contribución Territorial Rústica, sino que arranca desde el momento mismo de fijación de la cuota de la Seguridad Social Agraria, al determinarse ésta «en proporción a la base imponible» de aquella contribución (artículo 46, 3. ${ }^{\circ}$, de la repetida Ley de 31 de mayo de 1966), lo que ha venido a ser desarrollado por Decreto de 2 de febrero de 1967, que, después de repetir lo ordenado en ese texto legal, establece en su artículo $3 .^{\circ}$ que «la cuota correspondiente a cada empresario en el Régimen Especial Agrario de la Seguridad Social consistirá en un 15,9 por 100 de las bases imponibles...» de tan citada contribución, fijándole para el primer período del reparto una vigencia de cuatro años, a partir de 1 de enero de 1967 (artículo 4).

8. Que no sólo merece consideración este entronque íntimo de una cuota con otra, y el que, por tanto, toda la gestión de la de autos se realice a la vez que la de la cuota de la Contribución Rústica, sino que, por consecuencia de ello, a ojos del contribuyente, el pago de la cotización patronal o empresarial por este seguro obligatorio a favor de los trabajadores viene impuesto por la autoridad, la espectacularidad, nos atrevemos a decir, y la coactividad, propias del procedimiento ordinario de los tributos de la Hacienda estatal; no es lógico ni justo, por ello, el aprovechar todas las ventajas derivadas de una gestión tan expedita y autoritaria, para luego, en la contrapartida del contribuyente, dejar a éste casi inane, desprovisto de los medios de garantía establecidos precisamente para conectarlos con esos procedimientos de gestión tributaria, de los que. son una simple fase más.

9. Que, en efecto, si toda la gestión de estas cuotas en litigio, o por lo menos lo más importante de la misma, se realiza con una gestión tributaria por parte de órganos de la Hacienda pública, la propia lógica interna del sistema impone, mientras no aparezca un texto legal expreso en contrario, primero, que el contribuyente pueda disponer de garantía para poder impugnar cualquier extralimitación en la determinación y cobro de las cantidades basadas en este concepto, aunque no sea más que por respeto a la cláusula ge- 
neral de protección del administrado, reconocida en el artículo $1 .^{\circ}$ de nuestra Ley Jurisdiccional, artículo 42 de la Ley Orgánica del Estado y artículos 17 y 36 del Fuero de los Españoles, tal y como se ha recordado en un caso análogo al de autos por la misma Sala de Valladolid, y segundo, que esos medios de garantía sean los adecuados, puesto que precisamente en el ramo de la Hacienda pública estatal existe toda una larga tradición, de distinción y coordinación, entre las actividades de gestión y de resolución de las reclamaciones que contra la misma se susciten, lo que ha dado origen al nacimiento de los Tribunales Provinciales y Central, Económico-administrativos, conforme a lo dispuesto en el Real Decreto-Ley de 16 de junio de 1924 y en el Reglamento de 29 de julio del mismo año; que se continúa en el vigente de 26 de noviembre de 1959, todo ello como consecuencia de las directrices marcadas en el Real Decreto de 30 de agosto de 1901.

10. Que lo expuesto se ve reforzado por la circunstancia de que en las normas básicas de la Seguridad Social Agraria - Ley de 31 de mayo de 1966 y Reglamento de 23 de febrero de 1967- no se ha previsto nada sobre un régimen especial de garantías en esta materia; si bien es cierto que en el texto articulado II de la Ley de Bases de la Seguridad Social, aprobado por Decreto de 21 de abril de 1966, se atribuye en el número 2 del artículo $10^{\circ}$ a la jurisdicción del Trabajo, el conocimiento de los pleitos sobre «Seguridad Social», también es verdad que con ello se está pensando en las relaciones entre los elementos de la producción y las entidades gestoras, como relaciones inter privatos, dentro, claro está, del espíritu informante de todo el Derecho laboral, cuya clasificación, dentro de la clásica dicotomía «derecho público-derecho privado" es un tanto discutible; procedimiento laboral no instrumentado ciertamente para operar con él en la impugnación de actos administrativos, dictados por la Administración ejercitando una potestad que, por lo dicho más atrás, puede considerarse como potestad tributaria.

11. Que no enerva la tesis de la Sala el hecho de que en la Ley de 22 de diciembre de 1970, y en el texto refundido de 23 de julio de 1971, sobre la Seguridad Social Agraria, se inicie una tendencia dirigida a calcular las bases de estas cuotas sobre estimaciones propias, y no en función exclusiva y proporcionalmente matemática de las de la Contribución Territorial, puesto que, por un lado, estas disposiciones legales han entrado en vigor con posterioridad al mo- 
mento al que pertenecen los acuerdos recurridos, y por otro, porque tal espíritu independentista sólo lo ha sido parcialmente, siguiendo, por lo demás, insistiéndose en la fórmula de encomendar la gestión recaudatoria a las Entidades que vienen recaudando la Contribución Territorial, y aplicando los preceptos generales tributarios sobre recargo por apremio, intereses legales de demora y prescripción, y también porque nada se dice sobre medios impugnativos, anunciándose tan sólo (artículo $44,6^{\circ}$, del citado texto refundido de 23 de julio de 1971) que «reglamentariamente se regularán las circunstancias y condiciones de esta recaudación».

12. Que sentado lo anterior, la consecuencia es que a lo largo de estas vías, económico-administrativa y jurisdiccional, puede revisarse no sólo las posibles anomalías de la fase recaudatoria, sino también las cuestiones que puedan suscitar los presupuestos del acto liquidatorio, y entre ellos el planteado en estas actuaciones por el tan citado Ayuntamiento, al negar la condición de empresario agropecuario, como presupone la inclusión en el padrón por él mismo impugnado; problema certeramente resuelto, como el anterior, por la Sala de Primera Instancia, después de un detenido análisis de la prueba practicada al efecto, en el sentido de estimar la pretensión del mencionado Municipio, por haber probado él mismo que tal cuota se refiere a los montes "Corbejón y Quemados, Tamarizo Nuevo y Tamarizo Viejo», cuyos aprovechamientos fueron adjudicados a unos particulares, con sujeción a los planes previstos en la legislación de Montes y con arreglo a las instrucciones concretas del Distrito Forestal, siendo estos particulares los que tienen a su servicio a los asalariados necesarios, corriendo con las cargas de la Seguridad Social, por imponerla así el pliego de condiciones de las respectivas subastas, siguiendo de este modo el criterio sustentado por este Tribunal Supremo en su sentencia de 23 de marzo de 1971 (Aranzadi 1723).

Noveno. Que posteriormente la misma Sala Tercera del Tribunal Supremo dictó la sentencia de 27 de diciembre de 1972 (Arandazi 5321), en la que con ligeras variantes se mantuvo toda la extensa y clarividente teoría comentada en el número precedente, añadiendo en su considerando noveno argumentaciones tendentes a demostrar que al haberse verificado los aprovechamientos del Ayuntamiento reclamante, por medio de subastas explotadas por los adjudicatarios de los mismos, de hacerse pagar al Ayuntamiento 
la cuota empresarial daría lugar a una doble imposición, incompatible con los preceptos específicos que en dicho considerando se señalaban.

Décimo. Desde el mes de enero al de julio de 1973, la Sala de Burgos se pronunció en más de 60 sentencias, mandando excluir a los Municipios reclamantes de los padrones de la cuota empresarial del Régimen Especial de la Seguridad Social Agraria, sentencias que al no poder ser apeladas en razón a su cuantía, fueron recurridas en queja por la representación del Instituto Nacional de Previsión, y no aceptada la queja en aquellos casos en que quedó patente la certeza de la cuantía, al ser las cuotas reclamadas inferiores a la cantidad establecida como tope para poder exigir el requisito de las dos instancias ante el Tribunal Económico-administrativo, devinieron en firmeza.

Undécimo. Cuando ya parecía haberse sentado una definitiva doctrina, apareció la sentencia de 23 de marzo de 1973, en la que la Sala Cuarta del Tribunal Supremo, y con referencia al Ayuntamiento de Olmedo, declara que no ha lugar que el mismo quede exento del pago de la cuota empresarial, con referencia a los ejercicios de 1967 y 1968.

Duodécimo. Bien por desconocida, bien por entender que la evidente contradicción existe entre las dos sentencias de la misma Sala, la una, la ya referida de 23 de marzo de 1971 (Arandazi 1723), y la otra, la de 23 de marzo de 1973, podía restar validez al confrontamiento de ambas, bien por desconocerse en la última de ellas que no todas las circunstancias eran idénticas, ni las situaciones de los Municipios reclamantes iguales, bien quizá por seguir la línea de conducta establecida por las invocadas y concordes sentencias de la Sala Tercera del Tribunal Supremo, el caso es que las Salas de lo Contencioso de las Audiencias Territoriales de Burgos, Valladolid y Madrid, cuando menos, sin excluir la posibilidad de que otras lo hayan hecho en el mismo sentido, dictaron sentencias en las que se mantuvo la tesis que en la de 16 de diciembre de 1972 quedó perfectamente puntualizada.

Décimo tercero. Aquí se plantea lo que podemos llamar último capítulo, hasta el momento, de esta aparente divergencia de las decisiones jurisprudenciales, y cuando la Sala Tercera de lo Contencioso-administrativo, a la que no podemos suponer ignorando 
la sentencia de 23 de marzo de 1973 de la Sala Cuarta, tiene que pronunciarse sobre el recurso de apelación planteado por la Abogacía del Estado contra la sentencia favorable obtenida ante la Audiencia Territorial de Sevilla, por el Ayuntamiento de Conil de la Frontera, con fecha 5 de junio de 1973, dicta otra sentencia de la que es ponente el Excmo. Sr. D. Diego Espín y Cánovas, y se reitera la doctrina de dicha Sala, consignada en las sentencias de 15,16 y 27 de marzo de 1971, ya referenciadas, e invocando igualmente la de 23 de marzo de 1971, elude y calla la tesis contraria defendida por la de 23 de marzo de 1973, a la que tras esta última declaración en la línea de las anteriores debe considerarse como una apreciación excepcional motivada por razones quizá subjetivas, y no dentro de la temática general contemplada en todos los casos de Corporaciones que obtuvieron sentencias favorables.

\section{CONCLUSIONES}

Sin perjuicio de que el tema es de una extensión no ya de carácter monográfico, sino con entidad suficiente para constituir por sí solo una interesante aportación en el campo de los problemas de la patrimoniabilidad municipal, debemos, en atención a no hacer más extenso este ya largo estudio, concretar unas conclusiones, que bien pueden ser:

Primera. La inmensa mayoría de las Corporaciones locales sujetas al pago de la cuota empresarial del Régimen Especial Agrario de la Seguridad Social por la propiedad de sus montes y bienes catalogados como de utilidad pública, han mantenido una postura contraria a su inclusión en los padrones de la cuota empresarial del Régimen Especial Agrario de la Seguridad Social.

Segunda. Salvo en el caso que hemos enunciado, referente al Ayuntamiento de Olmedo, la inmensa mayoria de los hasta ahora reclamantes obtuvieron sentencias favorables, y en muchos casos les fueron devueltas las cuotas que ingresaron, o no cobradas las que dejaron de ingresar.

Tercera. Que alentadas dichas Corporaciones por los resultados favorables obtenidos, desean continuar en su contienda legal ante los Tribunales, con los órganos gestores de la Seguridad Social Agraria. 
Cuarta. Que esto, no obstante esta victoria, puede convertirse en ilusoria si para cada nuevo ejercicio han de mantener un nuevo recurso, con el consiguiente dispendio económico que ello lleva consigo.

Quinta. Que muchas Corporaciones que han obtenido sentencias favorables con declaraciones no de futuro, pero sí de baja en los padrones y que no se produzcan nuevas altas hasta que no se den las circunstancias contempladas en las partes dispositivas de los correspondientes fallos, las Corporaciones están dispuestas a producir denuncias, que en algunos casos ya se han presentado, con las que quizá pudiesen encausar a los gestores de la Seguridad Social Agraria, e incluso a la Delegación de Hacienda, por quebrantamiento de las decisiones judiciales.

Sexta. Que todo esto plantea un estado conflictivo entre las Corporaciones locales y el Ministerio de Trabajo que no dice nada en favor de las previsibles buenas relaciones entre la Administración Central y las Administraciones subordinadas.

Séptima. Cabe señalar un hecho que ha trascendido a la prensa diaria. Mientras que los cronistas de los Tribunales han consignado las noticias sin intervención alguna de las Corporaciones, señalando las sentencias favorables a ellas, por las que se informa no están obligadas al pago de la cuota empresarial de la Seguridad Social Agraria, la Mutualidad Agraria ha efectuado una actuación propagandística, incluyendo en la prensa de toda la nación, o cuando menos en la de las Provincias más afectadas, unos comentarios periodísticos que, basados en la sentencia de 23 de marzo de 1973, informan que los Ayuntamientos tienen que pagar, y si bien es cierto no faltan a la verdad para el caso concreto del Ayuntamiento de Olmedo y los ejercicios de 1967 y 1968, silencian toda la larga serie de situaciones, sentencias y pronunciamientos a que a lo largo de este estudio nos hemos referido en sentido literalmente contrario.

Octava. Debemos señalar que actualmente existen (subíndice) más de 100 recursos, concretamente de la Provincia de Soria, ante las Salas Tercera y Cuarta del Tribunal Supremo, y la inmensa mayoría de ellos por la declinación de la competencia de la Ley 10 de 1973, ante las Audiencias Territoriales, especialmente la de Burgos. 
Novena. Con posterioridad a las sentencias dictadas en la precedente, pero referidas al período que comprende los ejercicios 1967-1972, ambos inclusive, por diversos caminos se ha llegado a mantener una tesis uniforme por la que se ve claramente que las cuotas correspondientes a dichos ejercicios (1967-1972) no han de ser abonadas. Así, la Sala de lo Contencioso de Burgos ha dictado de enero a junio de 1974 más de cincuenta sentencias, determinándolo de esta manera. La de Valladolid, una de abril, cuyo comentario habremos de estudiar separadamente, y la Sala Sexta del Tribunal Supremo, dos (cuyas referencias de Aranzadi figuran a los números 100 y 114), cuya doctrina no puede ser, en el sentido afirmativo, más clara a la postura de no inclusión de los Municipios.

Para completar este estudio debe señalarse que, publicado el nuevo Reglamento de 23 de diciembre de 1972, aparecido en el mes de febrero de 1973, numerosísimas Corporaciones locales de toda España lo tienen impugnado, por entender que el mismo entraña, aparte de una infracción flagrante del ordenamiento jurídico, una auténtica desviación de poder, al pretender hacer uso de las potestades administrativas para supuestos diametralmente diferentes a aquellos que en la Ley de la Seguridad Social Agraria se establecieron como premisa de actuación en este campo.

Con esto entendemos haber producido una impresión de conjunto sobre un tema de indudable alcance y trascendencia en la vida corporativa local. 
REVL-1974, núm. 182. MORENO PAEZ, LEOCADIO-MANUEL. EXACCION DE LA CUOTA EMPRESAR...

REVL-1974, núm. 182. MORENO PAEZ, LEOCADIO-MANUEL. EXACCION DE LA CUOTA EMPRESAR... 